\title{
ADDED VALUE SAMPAH ORGANIK DENGAN TEKNOLOGI KOMPOSTER UNTUK MENINGKATKAN PENDAPATAN MASYARAKAT GAYO JEMBER-BONDOWOSO
}

\author{
Amri Gunasti ${ }^{1}$, Abadi Sanosra ${ }^{2}$ \\ Universitas Muhammadiyah Jember \\ amrigunasti@unmuhjember.ac.id*, abadi@unmuhjember.ac.id
}

\begin{abstract}
Waste generation in Jember and Bondowoso districts is estimated at more than $500 \mathrm{~m}^{3} / \mathrm{day}$. More than $70 \%$ is organic waste. It can have multiple effects. There are three main products produced from this program, the first is composter, the second is HCS bioactivator and the third is liquid compost. The approach method includes stages: a). Socialization of PKMS program on Composter and Compost Making Technology b). Preparation of social preconditions, i.e. Coordination with the Gayo Jember Community regarding solving problems faced by members c). Implementation of the Composter Making technology and compost technology application programs, both technical and non-technical for the community, d). Monitoring, evaluation and reporting. The implementation of the Community Stimulation Partnership Program (PKMS) Composter Technology and Household Scale composting will improve the optimization of household waste function as raw material for organic fertilizer, increasing the income and welfare of members of the Gayo Jember-Bondowoso Community.
\end{abstract}

Keywords: Composter; gayo society; organic trash; added value
Submit
Diterima
21 Juni 2020
15 Juli 2020
Dipublikasikan
31 Juli 2020

DOI : https://doi.org/10.33503/pambudi.v4i01.833

\section{ANALISIS SITUASI}

Jumlah sampah organik yang tidak tertangani tak sebanding dengan banyaknya jumlah limbah yang dapat ditangani TPA. Namun demikian, apabila terus menerus tidak tertangani maka ini akan menjadi akumulasi sampah organik, yang dapat memberi multi efek. Tentu saja ini belum terhitung tumpukan sampah yang belum diangkut ke TPA, atau sampah organik yang belum ditangani dengan baik oleh masyaraka Permasalahan ini merupakan tanggungjawa bersama, tidak hanya pemerintah tetapi juga masyarakat.

Mulanya, limbah rumah tangga dianggap sebagai sebuah permasalahan sepele oleh warga. Oleh karenanya tim pengabdian kepada masyarakat stimulus (PKMS) menawarkan solusi. Dengan adanya tawaran tersebut diharapkan masyarakat lebih memperatikan sekitarnya melalui gerakan mengelola limbah rumah tangga baik untuk keperluan sendiri atau secara kolektif sebelum berubah menjadi bencana. Kegiatan ini memberi hasil serta kegunaan yang sangat banyak yaitu dapat menghasilkan sampah organik untuk pupuk organik cair dan kompos dari tempat tinggal warga.

Karena akibat tidak baik dari limbah rumah tangga akan kembali lagi kepada warga, maka kepekaan dan keikutsertaan semua warga sangat diperlukan untuk mengatasi permasalahan itu secara sempurna dalam waktu yang singkat. Ada tiga produk utama yang yang diproduksi dalam kegitan ini, kesatu adalah komposter, yang kedua adalah HCS bioaktivator serta yang ketiga kompos cair. Selama ini masyarakat lebih banyak membuang sampah langsung ketempat sampah. Dengan program ini akan ada rekayasa teknik serta added value, sehingga sampai menjadi nilai tambah bagi masyarakat. Pengolahan sampah dengan cara ini dilakukan dengan tanpa mencacah, tidak perlu mengaduk, tidak perlu mesin khusus, 
tidak perlu tempat spesifik, tanpa aroma menyengat dan sangat mudah. Target khusus adalah mengelola sehingga berubah menjadi kompos dan merujuk pada usaha peduli sekitar. Target dari kegiatan ini adalah asal limbah terbanyak yakni keluarga. Sampah yang menjadi sasaran adalah limbah yang dapat menjadi pupuk organik yang bersumber dari kelebihan bahan masakan seperti: kulit mentimun, kangkung, buncis, selada, dan seterusnya. Selain itu juga berasal dari sisa buah-buahan seperti kulit apel, biji anggur, kulit terong belanda, kulit buah alpukat, kulit belimbing, dan sebagainya.

Hasil-hasil observasi terdahulu oleh Amri, $d k k$., Oktober 2015 dan hasil observasi bersama mitra dalam menentukan persoalan yang benar-benar merupakan permasalahan prioritas mitra adalah a) Pada umumnya masyarakat Gayo Jember-Bondowoso, belum memanfaatkan pekarangan rumah untuk pembuatan kompos dengan komposter, b) Minat masyarakat Gayo Jember-Bondowoso, untuk untuk pembuatan kompos dengan komposter masih rendah, c) Masyarakat Gayo Jember-Bondowoso, masih memiliki keterbatasan pengetahuan pada aspek teknis pembuatan komposter dan kompos, d) Masyarakat Gayo Jember-Bondowoso, belum mengetahui manfaat ekonomis dari kompos.

Salah satu infrastruktur yang sangat penting adalah tersedianya sarana dan prasarana pengelola sampah. Pengelolaan sampah merupakan masalah yang sangat pelik sehingga semua pihak harus terlibat dan berperan. Program Kemitraan Masyarakat Stimulus dengan judul Added Value Sampah Organik Dengan Teknologi Komposter Untuk Meningkatkan Pendapatan Masyarakat Gayo Jember-Bondowoso merupakan kegiatan dengan tujuan agar peran masyarakat menjadi lebih maksimal, khususnya masyarakat Gayo Jember-Bondowoso. Pengelolaan sampah tidak lagi tergantung kepada pemerintah, tetapi dapat dilakukan secara mandiri. Kegiatan ini langsung masuk kepersoalan utama lingkungan yaitu masalah sampah. Kegiatan ini akan menghasilkan teknologi yang paling tepat untuk menangani sampah khususnya sampah organik. Dengan terlaksananya kegiatan ini, maka kepedulian masyarakat terhadap lingkungan dapat diwujudkan, sehingga bencana alam dapat diantisipasi secara optimal. Secara keseluruhan keberadaan program ini sangat penting untuk mencapai renstra pengabdian masyarakat khususnya untuk bidang unggulan Infrastruktur Ramah Lingkungan dan Berkelanjutan.

Justifikasi pengusul bersama mitra masyarakat Gayo Jember-BondowosoBondowoso dalam menentukan persoalan prioritas adalah a) Teknologi komposter dan pembuatan kompos skala rumah tangga akan meningkatkan optimalisasi fungsi sampah rumah tangga sebagai bahan baku pupuk organik, b) Teknologi pembuatan komposter dan kompos skala rumah tangga dapat menigkatkan pendapatan anggota masyarakat Gayo Jember-Bondowoso, c) Adanya peningkatan pendapatan dan kesejahteraan anggota masyarakat Gayo JemberBondowoso dari sebelum adanya program Program Kemitraan Masyarakat Stimulus.

Jalan keluar yang diberikan bagi warga adalah pengunaan komposter dan pembuatan kompos. Jalan keluar yang diberikan itu mempunyai maksud agar terwujudnya kegunaan maksimal halaman rumah, meminimalisir limbah organik serta memaksimalkan penghasilan dan kemakmuran pada warga tujuan.

\section{METODE PELAKSANAAN}

Metode pelaksanaan yang dilakukan untuk mengatasi permasalahan masyarakat melalui kegiatan Kemitraan Masyarakat Stimulus ini adalah a) Sosialisasi Program Kemitraan Masyarakat Stimulus penerapan teknologi pembuatan komposter dan kompos, b) Persiapan prakondisi sosial, yakni koordinasi dengan masyarakat Gayo JemberBondowoso-Bondowoso, c) Pelaksanaan program aplikasi teknologi pembuatan komposter dan kompos baik teknis maupun 
non teknis bagi masyarakat, b) peninjauan, penilaian dan pembuatan laporan.

Langkah-langkah yang harus dilakukan untuk melaksanakan PKMS ini yakni, a) konsolidasi proses Program Kemitraan Masyarakat Stimulus kepada masyarakat, b) tahapan pengukuhan kemampuan SDM masyarakat Gayo Jember-Bondowoso melalui pelatihan Pembuatan Komposter dan kompos, c) tahap pengukuhan melalui pelatihan manajemen usaha pembuatan komposter dan kompos, d) penerapan prosedur dan tata laksana bisnis, yakni tahapan penerapan luaran, e) Asistensi mitra, yakni masyarakat Gayo Jember-Bondowoso dilapangan selama satu urutan proses pembuatan komposter dan kompos untuk menjamin aplikasi pembuatan komposter f) pengawasan, pembuatan laporan.

Rancangan aktivitas yang memperlihatkan tindakan jalan keluar dari permasalahan utama adalah a) Sosialisasi program Program Kemitraan Masyarakat Stimulus Pembuatan Komposter dan kompos, b) Kegiatan prakondisi sosial, melalui penguatan kapasitas Masyarakat Gayo Jember-Bondowoso-Bondowoso melalui pelatihan Pembuatan Komposter, meliputi Koordinasi dengan mitra: masyarakat Gayo Jember-Bondowoso, Penguatkan program masyarakat Gayo Jember-Bondowoso di lokasi Program Kemitraan Masyarakat Stimulus, Kegiatan dalam penerapan teknologi pembuatan komposter dan kompos.

Mitra Program Kemitraan Masyarakat Stimulus ini adalah masyarakat Gayo JemberBondowoso. Mitra berperan dalam program pembuatan komposter dan kompos karena sejalan dengan misi mitra. Program ini sekaligus menambah variasi program focus research dan create produk organic dan ramah lingkungan serta dalam rangka mitra usaha membuat produk lokal yang lebih unggul produk import di era globalisasi pasar. Masyarakat Gayo Jember-Bondowoso berkomitmen untuk melanjutkan kegiatan Program Kemitraan Masyarakat Stimulus secara berkelanjutan.
Ada tiga produk utama yang diperoleh dari kegiatan ini, yakni (1) komposter, (2) HCS bioaktivator, (3) kompos cair. Penerapan teknologi pembuatan komposter bagi aggota masyarakat Gayo Jember-Bondowoso baik secara individu maupun terhimpun dalam komunitas.

\section{HASIL DAN PEMBAHASAN}

\section{Persiapan PKMS}

Persiapan pelaksanaan kegiatan PKMS dimulai sejak tanggal 31 Desember 2019. Awal persiapan dilakukan koordinasi antara pelaksana dengan ketua masyarakat Gayo Jember Bondowoso. Dalam koordinasi tersebut disepakati bahwa satua diantara persoalan yang dialami oleh warga Gayo Jember Bondowoso adalah melimpahnya sampah organik yang dihasilkan oleh kegiatan sehari-hari. Terkait dengan keberadaan melimpahnya sampah organik tersebut ketua masyarakat Gayo Jember Bondowoso memaparkan beberapa permasalahan turunannya. Diantaranya tempat sampah yang ada masih belum memisahkan antara sampah kering dengan sampah organik. Disisi lain dari hasil diskusi antara pelaksana dengan ketua masyarakat Gayo Jember Bondowoso dikemukan bahwa sampah organik ini memiliki potensi ekonomis dengan melakukan added value. Untuk mendapatkan added value yang maksimal maka diperlukan teknologi tepat. Tim peneliti menyepakati bahwa teknologi yang paling tepat adalah membuat komposter yang mengubah sampah organik menjadi kompos.

Hasil dari koordinasi awal adalah ditandatanganinya surat kesediaan kerjasama program kemitraan masyarakat stimulus (PKMS) oleh ketua masyarakat Gayo Jember Bondowoso. Follow up dari kerjasama tersebut kemudian diadakan koordinasi antara tim pelaksana dengan segenap pengurus harian Masyarakat Gayo Jember Bondowoso pada tanggal 10 Januari 2020. Hasil koordinasi dengan pengurus harian ini disepakati bahwa pelaksanaan kegiatan 
PKMS akan dilaksanakan pada tanggal 9 Februari 2020.

\section{Pelaksanaan PKMS}

Dasar dari pelaksanaan PKMS ini adalah tahun anggaran 2020, Nomor 63/II.3.AU/LPPM/PPM/2020. Hasil kesepakatan antara Tim dengan Pengurus Harian Masyarakat Gayo Jember Bondowoso, PKMS ini dilaksanakan pada tanggal 9 Februari 2020. Pelaksanaan kegiatan ini bertempat di rumah Bapak Salman Arigayo, di jalan Raden Patah Gang XII, Nomor 155 Kelurahan Kepatihan, Kecamatan Kaliwates Jember (sebelah selatan SD Al-Furqon).

Tabel 1. Susunan acara PKMS

\begin{tabular}{crll}
\hline No & Waktu & \multicolumn{1}{c}{ Materi } \\
\hline 1. & $07.30-08$. & Pembukaan \\
\hline 2. & $08.30-09$. & Materi I: Pendampingan \\
& & Persiapan Bahan dan Alat \\
\hline 3. & $09.30-09$. & Coffee Break \\
\hline 4. & $09.45-12$. & Materi II: Pendampingan \\
& Pengelolaan Sampah \\
\hline 5 & $10.45-11$. & Materi III: Pendampingan \\
& Penggunaan Komposter \\
\hline 6. & $11.45-13$. & ISHOMA \\
\hline 7. & $13.00-14$. & $\begin{array}{l}\text { Materi IV: Pendampingan } \\
\text { Penggunaan Komposter }\end{array}$ \\
\hline 8. & $14.00-15$. & $\begin{array}{l}\text { Materi V: Pembuatan dan } \\
\text { Penggunaan HCS bioaktivator }\end{array}$ \\
\hline
\end{tabular}

Banyak pertanyaan yang diajukan oleh peserta PKMS mulai dari materi pertama sampai materi terakhir, ini artinya bahwa peserta sangat antusias mengikuti program ini, disebabkan sejauh ini tidak ada Tim yang berinisiatif untuk menghimpun Masyarakat Gayo Jember-Bondowoso untuk melakukan pendampingan pembuatan komposter ini. Mitra menganggap kegiatan ini sangat penting karena solusi yang ditawarkan sangat terkait langsung dengan masalah yang dihadapi.

Peranserta partisipan dalam kegiatan PKMS ini terbilang sangat besar, hal tersebut diperlihatkan oleh jumlah peranserta partisipan sebanyak $83,33 \%$ atau sebanyak 25 orang dari jumlah undangan yang disebar yaitu sebanyak 30 orang, berasal dari dua kabupaten yaitu kabupaten Jember dan kabupaten Bondowoso. Goal program PKMS ini adalah untuk menyediakan arah (guiding) bagi masyaraka Gayo Jember-Bondowoso mulai dari menyiapkan bahan dan alat, pengelolaan sampah, penggunaan komposter, pembuatan dan penggunaan HCS bioaktivator secara integratif sehingga bisa berdaya untuk mengatasi sampah organik serta menambah nilainya menjadi komposter yang dapat bernilai ekonomi.

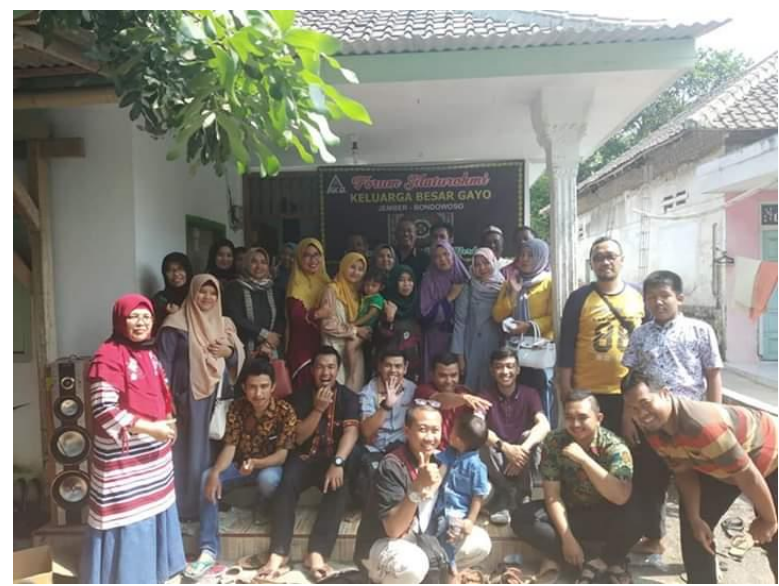

Gambar 1. Kegiatan PKMS

Pelaksanaan PKMS dilakukan dengan cara partisipatoris aktif yang mengutamakan tanya-jawab antara Tim PKMS dengan partisipan sehingga dimungkinkan peserta dapat memahami proses added value secara lebih detil. Peserta tidak hanya memperoleh pemahaman saja tetapi juga memperoleh keterampilah. Melalui kegiatan saling berinteraksi yang setara ini dimungkinkan dapat memotivasi partisipan agar sangat berperan yang pada akhirnya pengetahuan mengenai bahan training sangat cepat.

\section{Pelatihan Pembuatan Komposter}

Pelatihan yang dilaksanakan dengan mitra ini sangat aplikatif, sehingga mitra mampu dengan mudah mengaplikasikannya setelah pelatihan berakhir. Adapun materi yang disampaikan dalam kegiatan tersebut tertera pada tabel 2.

Tabel 2. Kegiatan dalam Penerapan Teknologi Pembuatan Komposter dan kompos 


\begin{tabular}{|c|c|}
\hline $\begin{array}{l}\text { Komponen } \\
\text { Teknologi }\end{array}$ & $\begin{array}{c}\text { Teknologi yang } \\
\text { direkomendasikan }\end{array}$ \\
\hline $\begin{array}{l}\text { Pembuatan } \\
\text { Komposter }\end{array}$ & \\
\hline $\begin{array}{l}\text { Bahan } \\
\text { Komposter }\end{array}$ & $\begin{array}{l}\text { galon, paralon, plastik akrilik, kain } \\
\text { kasa dan spon }\end{array}$ \\
\hline $\begin{array}{l}\text { Peralatan } \\
\text { Pembuat } \\
\text { Komposter }\end{array}$ & $\begin{array}{l}\text { gergaji besi, gergaji triplek, cutter, } \\
\text { bor tangan dan gunting. }\end{array}$ \\
\hline $\begin{array}{l}\text { Pembuatan } \\
\text { Komposter }\end{array}$ & $\begin{array}{l}\text { Langkah-langkah pembuatannya } \\
\text { adalah sebagai berikut : } \\
\text { a. Potong pipa dengan ukuran } 40 \\
\text { cm, lalu buat bolongan sesuai } \\
\text { kebutuhan dengan ukuran } \\
\text { jarak yang konsisten agar } \\
\text { terlihat rapi. Kegunaan } \\
\text { bolongan agar penyingkiran } \\
\text { gas, sekaligus agar angin } \\
\text { tembus disebabkan komposter } \\
\text { ini jenis aerob. } \\
\text { b. Kemudian bolongi dengan } \\
\text { ukuran sama dengan diameter } \\
\text { pipa dengan buntuk bulatan } \\
\text { dnegan menggunakan alat } \\
\text { pemotong. } \\
\text { Bikin bolongan untuk kran, } \\
\text { dengan ukuran } 3 \text { cm. } \\
\text { d. Selanjutnya bikn filter } \\
\text { memakai benda gabus yang } \\
\text { sudah tidak terpakai. } \\
\text { e. Gunakan kain putih yg } \\
\text { tenunannya jarang, sebagai } \\
\text { pembungkus bolongan pipa } \\
\text { untuk filter agar kuman, } \\
\text { bakteri dan hewan kecil tidak } \\
\text { bisa masuk. } \\
\text { Bikin tempat sebagai sandaran } \\
\text { filter. }\end{array}$ \\
\hline $\begin{array}{l}\text { Pengelolaan } \\
\text { Sampah }\end{array}$ & $\begin{array}{l}\text { Cara Mengelola Sampah dengan } \\
\text { Komposter adalah sebagai berikut: } \\
\text { 1. Sortir limbah Organik } \\
\text { 2. Masukkan limbah organik } \\
\text { yang telah di sortir kedalam } \\
\text { pipa } \\
\text { 3. Suntikan secara merata HCS } \\
\text { bioaktivator } \\
\text { 4. Beri penyumbat/penutup } \\
\text { tabung secara erat } \\
\text { 5. menuai kompos jika telah } \\
\text { melimpah } \\
\text { 6. Tadah kompos likuid pra } \\
\text { dipakai } \\
\text { 7. Kompos cair siap dipakai }\end{array}$ \\
\hline
\end{tabular}

\begin{tabular}{|c|c|}
\hline & $\begin{array}{l}\text { 8. gunakan } 200 \mathrm{ml} \text { kompos } \\
\text { likuid } \\
\text { 9. Aduk menggunakan 5-10 liter } \\
\text { pelarut } \\
\text { 10. gunakan pada tumbuhan } \\
\text { 11. dapat dikemas dengan baik } \\
\text { untuk dijual }\end{array}$ \\
\hline $\begin{array}{l}\text { Penggunaan } \\
\text { Komposter }\end{array}$ & $\begin{array}{l}\text { Cara Penggunaan Komposter } \\
\text { adalah sebagai berikut: } \\
\text { 1. Buka sumbat tabung, } \\
\text { masukkan limbah yang telah } \\
\text { disortir ke bagian dalam } \\
\text { tabung. (limbah organik bisa } \\
\text { dalam keadaan sempurna atau } \\
\text { utuh atau bisa juga sebaliknya } \\
\text { dalam keadaan sudah } \\
\text { dipotong-potong) }\end{array}$ \\
\hline
\end{tabular}

2. Suntikan secara merata HCS bioaktivator

3. Selalu masukkan limbah daun-daunan, sayur-sayuran dan buah-buahan ke dalam tabung.

4. Selalu usahakan penutup tabung setiap saat dalam kondisi tertutup erat.

5. Selalu memantau pipa kecil tempat mengeluarkan cairan kompos tumbuhan, jika sudah terlihat pada pipa kecil, bisa diambil supaya bisa dimanfaatkan untuk kompos tanaman

\begin{tabular}{ll}
\hline $\begin{array}{l}\text { Pembuatan } \\
\text { dan }\end{array}$ & $\begin{array}{l}\text { Cara Pembuatan dan Penggunaan } \\
\text { Penggunaan }\end{array}$ \\
HCS & HCS bioaktivator adalah sebagai \\
bioaktivator & 1.
\end{tabular}

3. Campurkan larutan itu ke dalam tabung (composter) sampai basah pada bagian atas limbah setiap seminggu 1 kali.

4. Simpan setiap saat semprotan pada tempat yang dingin/sejuk. 


\section{Hasil Yang Dicapai}

Program kemitraan masyarakat stimulus (PKMS) dilaksanakan secara partisipatoris aktif. Dalam setiap penyampaian materi, peserta langsung dapat berinteraksi dengan fasilitator. Dari pertanyaan dan pernyataan diketahui bahwa sebagian peserta sudah mengetahui mengenai teknologi komposter dan sebagian lagi tidak tahu sama sekali. Peserta yang mengetahui teknologi komposter juga bermacam-macam tingkatannya, beberapa pernah melihat secara langsung, sebagian pernah melihat dimedia baik media cetak maupun media sosial. Secara keseluruhan peserta sebelumnya belum pernah membuat dan mempraktekkan cara membuat teknologi komposter. Dengan program kemitraan masyarakat stimulus (PKMS) keseluruhan peserta mengetahui mengenai teknologi komposter ini. Pengetahuan peserta setelah pelaksanaan kegiatan juga bervariasi. Ada yang mengetahui proses pembuatannya, ada juga yang mendapatkan keahlian membuatnya.

Secara lebih rinci Masyarakat Gayo Jember-Bondowoso dapat mengetahui, memahami dan mendapatkan keahlian mempersiapkan Bahan dan Alat. Masyarakat Gayo Jember-Bondowoso dapat mengetahui, memahami dan mendapatkan keahlian membuat Komposter. Selanjutnya manfaay yang diperoleh dari kegiatan tersebut yakni Komunitas Gayo Jember-Bondowoso mengetahui, memahami dan mendapatkan keahlian dalam pengelolaan Sampah. Masyarakat Gayo Jember-Bondowoso mengetahui, memahami dan mendapatkan keahlian dalam penggunaan Komposter. Masyarakat Gayo Jember-Bondowoso mengetahui, memahami dan mendapatkan keahlian dalam pembuatan dan Penggunaan HCS bioaktivator.

Peserta juga diberikan pelatihan manajemen usaha Pembuatan Komposter dan kompos. Manajemen usaha ini sangat penting bagi keberlanjutan program ini untuk jangka panjang. Karena potensi ekonomis dari program ini sangat besar, maka peserta diharapkan mampu mengevaluasi secara terus menerus, sehingga nilai ekonomisnya terus bertambah, seiring berjalannya waktu. Dari interaksi peserta memahami bagaimana memanajemen dan mempertahankan usaha ini. Peserta juga memahami bagaimana agar kegiatan ini memberi dampak yang luas bagi masyarakat sekitarnya, sehingga diharapkan teknologi komposter ini dapat dilakukan oleh masyarakat yang lebih luas lagi. Secara keseluruhan diharapkan dampak dari kegiata ini semakin menambah manfaat baik, ekonomis, sosial dan lingkungan baik bagi peserta maupun bagi masyarakat umum.

\section{KESIMPULAN}

Dari pelaksanaan program kemitraan masyarakat stimulus (PKMS) dapat disimpulkan bahwa:

a) Teknologi Komposter dan pembuatan kompos Skala Rumah Tangga akan meningkatkan optimalisasi fungsi sampah rumah tangga sebagai bahan baku pupuk organik.

b) Teknologi pembuatan Komposter dan kompos Skala Rumah Tangga dapat menigkatkan pendapatan anggota Masyarakat Gayo Jember-Bondowoso.

c) Bila dilakukan berkelanjutan, Teknologi Komposter akan meningkatkan pendapatan dan kesejahteraan Anggota Masyarakat Gayo Jember-Bondowoso.

\section{Ucapan Terima Kasih}

Ucapan Terima kasih disampaikan kepada Pusat Penelitian dan Pengabdian Masyarakat (LPPM) Universitas Muhammadiyah Jember yang telah mendukung pendanaan dalam pelaksanaan program kemitraan masyarakat stimulus (PKMS) ini.

\section{DAFTAR PUSTAKA}

Aklis, N., \& Masyrukan, M. (2016). Penanganan Sampah Organik Dengan Bak Sampah Komposter di Dusun Susukan Kelurahan 
Susukan Kecamatan Susukan Kabupaten Semarang. Warta LPM, 19(1), 74-82.

Balai Teknik Air Minum dan Sanitasi Wilayah 2, Wiyung, Surabaya. (2010). Materi Pelatihan Berbasis Kompetensi Bidang Persampahan.

Guslan, D. A. (2020). INOVASI KOMPOSTER SEBAGAI UPAYA PENGELOLAAN SAMPAH DI KELURAHAN GEDAWANG SEMARANG, JAWA TENGAH. Jurnal Pasopati, 2(2).

Heru Santoso (2014). kelola sampah jadi berkah. Berita Tangsel.com, 1 Februari 2014.

Jaelani, A., Purwanti, H. I., \& Aziz, M. R. (2011). Pemanfaatan Komposter Sederhana sebagai Solusi Alternatif Mengatasi Sampah di Perumahanpodosugih Kota Pekalongan. In Pekan Ilmiah Mahasiswa Nasional Program Kreativitas MahasiswaPengabdian Kepada Masyarakat 2013. Indonesian Ministry of Research, Technology and Higher Education.

Kustiani, I., Siregar, A. M. R., Widyawati, R., Susilo, G. E., \& Kusnadi, A. (2018). Pemberdayaan Kelompok Tani Kelurahan Rajabasa Jaya Melalui Pelatihan Pembuatan Komposter Mini Bernilai Ekonomi.

Mutaqin, T. H. (2010). Pengelolaan sampah limbah rumah tangga dengan komposer elektrik berbasis komunitas. Jurnal Litbang Sekda DiY Biro Adm. Pembang, 2(2), 1-12.

Pujiati, R. S., \& Moelyaningrum, A. D. KAJIAN POTENSI PEMANFAATAN SAMPAH KABUPATEN JEMBER SEBAGAI BAHAN KOMPOS DAN BRIKET.

Raharjo, S., Ihsan, T., \& Yuned, S. R. (2017). Pengembangan Pengelolaan Sampah Perkotaan dengan Pola Pemanfaatan Sampah Berbasis Masyarakat. Jurnal Dampak, 13(1), 10-25.

Trisakti, B., \& Sijabat, I. P. (2020). Profil pH dan Volatile Suspended Solids pada Proses Pengomposan Tandan Kosong Kelapa Sawit Menggunakan Pupuk Cair Organik Aktif sebagai co-Composting. Jurnal Teknik Kimia USU, 9(1), 11-15.

Umarie, I. I., \& Gunasti, M. A. (2016). IbM ANGGOTA PKK MELALUI PENERAPAN TEKNOLOGI BUDIDAYA SAYUR SECARA VERTIKULTUR DI
KECAMATAN KALIWAT ES KABUPATEN JEMBER. Jurnal Pengabdian Masyarakat IPTEKS, 1(1). 